\title{
'Sustainability' of Sustainable Development Discourse (With Special Focus on Community Based Eco-tourism in the Sinharaja Rain Forest)
}

\author{
H.I.G.C. Kumara \\ Department of Geography, University of Ruhuna, Sri Lanka \\ ckh10@students.waikato.ac.nz
}

\begin{abstract}
Community based eco-tourism (CBET) is a well-established concept that based on sustainable development discourse and its implementation has been an important component for many regional development and eco-system management strategies. This research paper argues that CBET under the sustainable development discourse has originated as a western concept, however, CBET operates within diversgeo-political, economic and cultural contexts, which generate challenges to achieve realistic goals of sustainable development discourse. This research examines a CBET initiative in the Kudawa- Sinharaja site, Sri Lanka which shifted in 1995 from a central government approach under the forestry sector master plan, in line with western CBET and sustainable development ideologies.
\end{abstract}

A qualitative approach has principally guided this research together with quantitative analysis to examine the socio-cultural, socio-economic and geo-political context. A total of 293 participants have provided information for this research, which includes 193 interviews (115 individuals, and 15 different focus groups totalling 78 people) and 100 questionnaire respondents. These participants were surveyed during late 2012 and early 2013, and included both domestic and overseas tourists, local community residents and tourist operators, tourism consultants, and government officials. A critical discourse analysis (CDA) method was used to examine both primary qualitative data, which were collected through participant and direct observation, interviews as well as secondary data. One of the main findings is that despite plans being developed at a community level, the wider context includes superimposed capitalism, which dominates and counteracts the ideologies of sustainable development discourse. Superimposed capitalism results in individualistic and competitive behaviours that undermine the collaborative community approach. It encourages poaching and the selling of rare flora and fauna (biopiracy), and results in anthropogenic disturbances to nature.

Further, this research also highlights the strong influence of geo-politics, which operates at both the international and domestic scale. Political corruption, access to funds, and the lack of established decision making processes are also associated with geo-politics. This research also underlines the influence of the socio-cultural context such as gender inequality and caste discrimination, which substantially disempower certain people. The research concludes that sustainable development discourseis a phantasy ideology if not to be addressed, in particular, superimposed capitalism, socio-cultural and geo-political issues in the particular areas. The findings of this research will inform CBET in similar developing countries, but caution is required because the geo-political, economic and cultural context is different in every country.

Keywords: Sustainable development discourse, Community based eco-tourism 